\title{
Response to: Assessment of frailty in geriatric patients: let's keep it simple
}

\author{
Merete Gregersen $^{1}\left[\right.$. Troels Kjærskov Hansen ${ }^{1}\left[\right.$ · Bodil Bæksted Jørgensen ${ }^{1} \cdot$ Else Marie Damsgaard ${ }^{1}[0$
}

Received: 4 August 2020 / Accepted: 14 August 2020 / Published online: 28 August 2020

(c) European Geriatric Medicine Society 2020

With gratitude we have read the letter by Bruno et al. [1] commenting on our article "Frailty is associated with hospital readmission in geriatric patients: A prognostic study" [2]. As stated by the opponents frailty assessment is essential in the management of older patients suffering from acute illness. However, frailty assessment is complex due to many dimensions of the patient's health and daily life.

The Comprehensive Geriatric Assessment (CGA) is a corner stone in the multi-disciplinary working process of getting a 360-degree view on the health status of an older patient. CGA is defined as 'a multi-dimensional, multi-disciplinary diagnostic and therapeutic process conducted to determine the medical, mental, and functional problems of older people with frailty so that a coordinated and integrated plan for treatment and follow-up can be developed' [3]. The Multidimensional Prognostic Index is based upon the CGA, and is a method to systematically assess geriatric patients.

In geriatric departments, CGA is a well-established working method producing identification and quantification of the problems of older patients followed by personalized interventions [4]. During hospitalization, the MPI creates an overview of the needed clinical decisions and of which initiatives that should be initiated for the patients immediately after discharge such as need for home care and rehabilitation.

In recent years, the CGA has been further refined by validated testing. In the next few years, entering the CGAdomains directly into the patients' electronical medical chart is likely to become an integrated part of treatment, thereby providing the foundation for time saving and automatized frailty assessment. The MPI assessment provides a highly standardized and more comprehensive frailty assessment

This comment refers to the article available online at https://doi. org/10.1007/s41999-020-00360-9.

Merete Gregersen

meregreg@rm.dk

1 Department of Geriatrics, Aarhus University Hospital,

Aarhus, Denmark than the Clinical Frailty Scale (CFS). We believe both the CFS and the MPI are applicable and worth considering in the assessment of frailty under various circumstances.

Finally, it is correct that frailty is associated with higher age. However, not all of the oldest old are frail, and do not need the same level of attention as a frail patient of similar or even younger age.

\section{Compliance with ethical standards}

Conflict of interest The authors declare that they have no conflicts of interest.

Ethical approval This letter does not contain any studies with human participants or animals performed by any of the authors.

Informed consent For this type of letter formal consent is not required.

\section{References}

1. Bruno RR, Wernly B, Guidet B, Flaatten H, De Lange DW, Jung C (2020) Assessment of frailty in geriatric patients: let's keep it simple. Eur Geriatr Med 2020:1-2

2. Gregersen M, Hansen TK, Jorgensen BB, Damsgaard EM (2020) Frailty is associated with hospital readmission in geriatric patients: a prognostic study. Eur Geriatr Med. https://doi. org/10.1007/s41999-020-00335-w

3. Ellis G, Gardner M, Tsiachristas A, Langhorne P, Burke O, Harwood RH et al (2017) Comprehensive geriatric assessment for older adults admitted to hospital. Cochrane Database Syst Rev 9:CD006211

4. Solomon DH (1988) Geriatric assessment: methods for clinical decision making. JAMA 259(16):2450-2452

Publisher's Note Springer Nature remains neutral with regard to jurisdictional claims in published maps and institutional affiliations. 